\title{
Clinical Presentation of Asymptomatic and Mild SARS-CoV-2 Infection in Riyadh, Saudi Arabia
}

\author{
Khalid A Bin Abdulrahman (1D' \\ Abdullah $O$ Bamosa $\mathbb{1 D}^{2}$ \\ Khaled S Aseri ${ }^{3}$ \\ Abdullah I Bukhari ${ }^{4}$ \\ Emad M Masuadi (iD ${ }^{5}$ \\ 'Department of Medical Education and \\ Department of Internal Medicine, College \\ of Medicine, Imam Mohammad Ibn Saud \\ Islamic University, Riyadh, Saudi Arabia; \\ ${ }^{2}$ Department of Physiology, College of \\ Medicine, Imam Abdulrahman Bin Faisal \\ University, Dammam, Saudi Arabia; \\ ${ }^{3}$ Department of Preventive Medicine, \\ Faculty of Medicine, King Saud bin \\ Abdulaziz University for Health Sciences, \\ King Abdulaziz Medical City, Jeddah, \\ Saudi Arabia; ${ }^{4}$ Department of Medicine, \\ Infectious Diseases Division, College of \\ Medicine, Imam Mohammad Ibn Saud \\ Islamic University, Riyadh, Saudi Arabia; \\ ${ }^{5}$ Research Unit, College of Medicine, \\ King Saud Bin Abdulaziz University for \\ Health Sciences, Riyadh, Saudi Arabia
}

Background: There is substantial evidence that most SARS-CoV-2 infections are mild or even asymptomatic, yet they can transmit the virus to others. The current study described the clinical presentation of mild COVID-19 cases isolated in the ministry of health (MOH) quarantines in Riyadh, Saudi Arabia.

Methods: A cross-sectional study targeted the SARS-CoV-2 PCR + ve asymptomatic and mild COVID-19 patients isolated in the Saudi MOH quarantines in Riyadh city between July and December 2020. The confirmed COVID-19 patients were enrolled and interviewed by telephones after obtaining the informed consent.

Results: The study included 223 patients with a mean age of $32.5 \pm 10.7$ years old. The majority were male 156 (70\%). Only 27 [12.1\%; 95\% CI = (8.1-17.1\%)] were asymptomatic. General fatigue was the most common reported symptom, $43.5 \%$, followed by headache with $42.6 \%$, and cough by $38.1 \%$. Anosmia and ageusia were reported by $33.2 \%$ and $31.4 \%$, respectively. The least common reported symptoms were vomiting, earache, and nausea with $1.8 \%, 4.0 \%$, and $7.6 \%$, respectively.

Conclusion: The top five clinical manifestations of mild COVID-19 cases were general fatigue, headache, cough, anosmia, and ageusia. Only 12\% of confirmed COVID-19 cases were asymptomatic.

Keywords: mild COVID-19, clinical presentations, anosmia, ageusia, Saudi Arabia

\section{Introduction}

Coronavirus disease 2019 (COVID-19) is a newly recognized illness detected in Wuhan, Hubei province, China, and spread rapidly worldwide. ${ }^{1-3}$ COVID-19 is initially characterized by fever, sore throat, cough, and dyspnea, mainly the respiratory system's manifestations. ${ }^{4-6}$ A recent meta-analysis $(n=3598$ patients) reported that around $11 \%-14 \%$ of the COVID-19-related symptoms are headaches in patients who had either died or recovered. ${ }^{7-9}$ In Beijing, a series of 262 confirmed cases of the COVID-19, fever, cough, fatigue, dyspnea, and headache with a rate of $6.5 \%$ were the most common symptoms at the onset of illness. ${ }^{10}$ Anosmia has already been reported in the course of COVID-19 and other SARS-CoV-2 infections. ${ }^{11,12}$ In COVID-19 patients, ageusia, and anosmia are not accompanied by nasal obstruction or other rhinitis symptoms. Therefore, this is probably due to the virus's direct damage to the olfactory and gustatory receptors. ${ }^{13,14}$ Another Chinese multicenter study enrolling 204 patients until early March 2020, 103 patients (50.5\%) reported digestive symptoms, including lack of appetite (81 [78.6\%] cases), diarrhea (35 [34\%] cases), vomiting (4 [3.9\%] cases), and abdominal pain (2 [1.9\%] cases). ${ }^{15}$ The current study aims to
Correspondence: Khalid A Bin Abdulrahman

Department of Medical Education and Department of Internal Medicine, College of Medicine, Imam Mohammad Ibn Saud Islamic University, Riyadh, Saudi Arabia Email kab@imamu.edu.sa 
describe the clinical presentations of patients with mild COVID-19 in Riyadh, Saudi Arabia.

\section{Subjects and Methods}

This study was part of an interventional clinical trial aiming to examine the efficacy of black seeds on the Immunity of mild COVID-19 patients.

\section{Study Population}

The study was conducted on mild or asymptomatic COVID-19 patients isolated in Al Izdihar Holiday Inn Hotel quarantine and Marriott Hotel quarantine in Riyadh city, between July and December 2020. A total of 223 patients fulfilling the inclusion and exclusion criteria were included in the study. Inclusion criteria were: (1) Age 18 up to 85 years (2) Positive SARS-CoV-2 PCR diagnostic test (3) Mild COVID-19 disease, defined as laboratory-confirmed severe acute respiratory syndrome coronavirus-2 (SARS-CoV-19) case and any COVID-19 related symptoms with no oxygen requirement or evidence of pneumonia. (4) Asymptomatic SARS-CoV-2 infection, defined as a laboratory-confirmed SARS-CoV-2 case with no symptoms. The exclusion criteria were: (1) History of drug addiction or (2) Pregnant and lactating women or (3) Malignancy or (4) Chronic illnesses except for hypertension and diabetes mellitus or (5) Moderate to severe respiratory distress requiring respiratory or critical care supports. All patients agreeing to participate were asked to sign a written consent form. Qualified health practitioners carried out a thorough history and clinical examination. Patients were interviewed by telephone to fill a prepared questionnaire in Arabic and English using Survey Monkey platform. The questionnaire included demographic information, history of illnesses, immunization history, immunity-related questions, body mass index, and detailed COVID-19 related symptoms.

\section{Statistical Analysis}

Data were entered and analyzed using IBM SPSS Statistics for Windows, Version 25.0. Armonk, NY: IBM Corp. Categorical data were presented as counts and percentages, and numerical data presented as mean $( \pm \mathrm{SD})$. A Chisquare test was used to assess the association between patients' characteristics and symptomatology. A test with a p-value less than 0.05 was considered statistically significant.

\section{Results}

The study included 223 COVID-19 patients with a mean age of $32.5 \pm 10.7$ years old. Almost half of the patients were between 18 to 29 years old. The majority were male, $156(70 \%)$, and around three-quarters were Saudi. Onethird of patients were within the normal BMI, and onethird were overweight (Table 1). Only 12 (5.4\%) patients traveled outside KSA during the last six months. The majority of patients, $152(68.2 \%)$, never smoked any tobacco. Only three patients had a history of Malaria infection. Eighty-four patients (37.7\%) had close contact with confirmed COVID-19 cases, and 99 (44.4\%) were unsure if they had close contact. The majority of patients, $144(64.6 \%)$, reported taking medication or Vitamins (Table 2). Out of the 223 patients, only 27[12.1\%; 95\% $\mathrm{CI}=(8.1-17.1 \%)]$ were Asymptomatic. The symptoms reported by the remaining 196 patients are presented in Figure 1. General fatigue was the most common reported symptom by $43.5 \%$, followed by headache with $42.6 \%$, and then cough by $38.1 \%$. Loss of smell and taste were reported by $33.2 \%$ and $31.4 \%$, respectively. The least common reported symptoms were vomiting, earache, and nausea with $1.8 \%, 4.0 \%$, and $7.6 \%$, respectively. There was no statistically significant association between any of the patients' characteristics and symptomatology (all p-values $>0.05$ ) (Table 3).

\section{Discussion}

This study focused on the clinical presentations of mild COVID-19 patients admitted to the MOH quarantines in Riyadh, Saudi Arabia. According to the latest Saudi demographic survey, the majority of the Saudi population is under the age of 60 , which was reflected in the present study population's sociodemographic characteristics. The mean age is $32.5 \pm 10.7$ years old, and almost half of them were between 18 to 29 years old.

The association between COVID-19 and obesity was evident in the current study as the majority (64\%) of patients were either overweight or obese. This finding is supported by a recent systematic review and meta-analysis that found an association between obesity and poor composite outcome in COVID-19 patients. ${ }^{16}$ As the data on smoking and SARS-CoV-2 infection is still growing, almost one-third of the study populations have used tobacco products. ${ }^{17}$ The majority of the study population has not reported any close contact with confirmed COVID19 cases. The primary mode of COVID-19 transmission is 
Table I Patients' Baseline Characteristics

\begin{tabular}{|c|c|c|c|}
\hline & & $\mathbf{N}$ & $\%$ \\
\hline \multirow[t]{2}{*}{ Sex } & Male & 156 & $70.0 \%$ \\
\hline & Female & 67 & $30.0 \%$ \\
\hline \multirow[t]{3}{*}{ Age (years) } & $<30$ & 109 & $48.9 \%$ \\
\hline & $30-39$ & 55 & $24.7 \%$ \\
\hline & $40+$ & 59 & $26.5 \%$ \\
\hline \multirow[t]{2}{*}{ Nationality } & Saudi & 173 & $77.6 \%$ \\
\hline & Non-Saudi & 50 & $22.4 \%$ \\
\hline \multirow[t]{4}{*}{ Body mass index groups } & Underweight & 4 & $1.8 \%$ \\
\hline & Normal weight & 75 & $34.1 \%$ \\
\hline & Overweight & 78 & $35.5 \%$ \\
\hline & Obese & 63 & $28.6 \%$ \\
\hline Age & Mean $\pm S D$ & 32.5 & \pm 10.7 \\
\hline Pulse rate & Mean $\pm S D$ & 89.7 & \pm 11.4 \\
\hline Systolic & Mean \pm SD & 122.5 & \pm 12.6 \\
\hline Diastolic & Mean \pm SD & 80.9 & \pm 9.8 \\
\hline Temperature Celsius & Mean \pm SD & 36.8 & \pm 0.6 \\
\hline Respiratory rate & Mean $\pm S D$ & 17.8 & \pm 7.1 \\
\hline
\end{tabular}

Table 2 Patients' Past History

\begin{tabular}{|c|c|c|c|}
\hline & & $\mathbf{N}$ & $\%$ \\
\hline \multirow{2}{*}{ Travel history outside KSA during the last six months? } & No & 211 & $94.6 \%$ \\
\hline & Yes & 12 & $5.4 \%$ \\
\hline \multirow[t]{3}{*}{ Smoke or use tobacco products } & No & 152 & $68.2 \%$ \\
\hline & Yes & 61 & $27.4 \%$ \\
\hline & Ex-smoker & 10 & $4.5 \%$ \\
\hline \multirow[t]{4}{*}{ Number of Flu per year } & I time & 109 & $48.9 \%$ \\
\hline & 2 times & 82 & $36.8 \%$ \\
\hline & 3 times & 24 & $10.8 \%$ \\
\hline & More than 3 times & 8 & $3.6 \%$ \\
\hline \multirow[t]{3}{*}{ Did you have a Malaria infection before? } & No & 220 & $98.7 \%$ \\
\hline & Yes & 3 & $1.3 \%$ \\
\hline & Not sure & 0 & $0.0 \%$ \\
\hline \multirow[t]{3}{*}{ Did you have any chronic infection before? } & No & 168 & $75.3 \%$ \\
\hline & Yes & 3 & $1.3 \%$ \\
\hline & Not sure & 52 & $23.3 \%$ \\
\hline \multirow{3}{*}{$\begin{array}{l}\text { Did any of your close contact members have had COVID-19 infection } \\
\text { before? }\end{array}$} & No & 40 & $17.9 \%$ \\
\hline & Yes & 84 & $37.7 \%$ \\
\hline & Not sure & 99 & $44.4 \%$ \\
\hline \multirow{2}{*}{$\begin{array}{l}\text { Is the subject currently or previously taking any medication, including OTC, } \\
\text { Vitamins, and/or supplements? }\end{array}$} & No & 79 & $35.4 \%$ \\
\hline & Yes & 144 & $64.6 \%$ \\
\hline
\end{tabular}




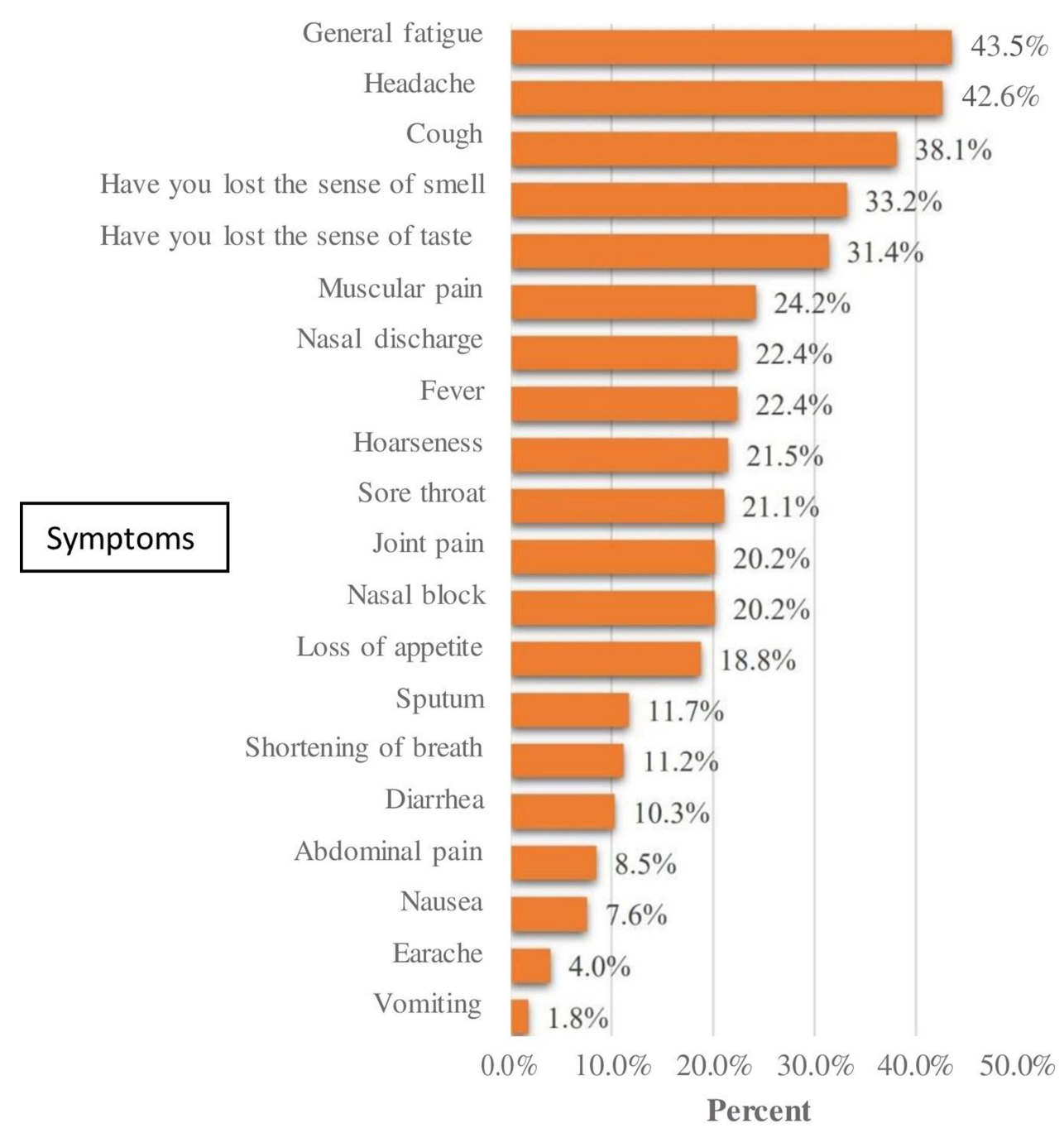

Figure I Clinical presentation of the symptomatic individuals with mild COVID-19.

via exposure to infected droplets. The virus spreads via respiratory droplets from infected individuals while sneezing, coughing, or talking without covering the mouth and the nose. ${ }^{18}$ With the global pandemic of COVID-19, there is substantial evidence that many infections of SARS$\mathrm{CoV}-2$ are mild or even asymptomatic. Yet, they can transmit the virus to others. ${ }^{19}$

The present study showed that out of the 223 patients, only $27[12.1 \% ; 95 \% \mathrm{CI}=(8.1-17.1 \%)]$ were asymptomatic. This could be explained by the fact that most of the study population was either overweight or obese. Kim et al found that asymptomatic individuals with COVID-19 are about $20 \%$. Hence, their data fill an important gap concerning the prevalence of asymptomatic individuals who constitute the disease pyramid. ${ }^{20}$ Previous studies reported that viable SARS-CoV-2 was isolated from symptomatic individuals. Certain groups of infections had been transmitted from asymptomatic patients; ${ }^{21,22}$ therefore, the notably high proportion of asymptomatic individuals in Kim's finding further supports the value of social distancing in controlling the current pandemic. The present study reveals no significant association between patients' characteristics and any COVID-19 related symptoms (all p-values $>0.05)$. Symptoms have been reported in 196 (88\%) patients in the current study.

General fatigue was the most common symptom reported by $43.5 \%$, followed by headache with $42.6 \%$, and cough by $38.1 \%$. Loss of smell was reported by $33.2 \%$, whereas loss of taste by $31.4 \%$ of patients. The least common reported symptoms were vomiting, earache, and nausea with $1.8 \%, 4.0 \%$, and $7.6 \%$, respectively.

Anosmia and ageusia are related to a wide range of viral infections. $^{23,24}$ The upper respiratory tract infection can cause acute-onset anosmia or ageusia because of viral 
Table 3 Association Between Patients' Characteristics and Asymptomatic

\begin{tabular}{|c|c|c|c|c|c|c|}
\hline & & \multicolumn{4}{|c|}{ Asymptomatic } & \multirow[t]{3}{*}{ P-value } \\
\hline & & \multicolumn{2}{|c|}{ Asymptomatic } & \multicolumn{2}{|c|}{ Symptomatic } & \\
\hline & & $\mathbf{N}$ & $\%$ & $\mathbf{N}$ & $\%$ & \\
\hline \multirow[t]{2}{*}{ Sex } & Male & 23 & 14.7 & 133 & 85.3 & 0.075 \\
\hline & Female & 4 & 6.0 & 63 & 94.0 & \\
\hline \multirow[t]{3}{*}{ Age (years) } & $<30$ & 15 & 13.8 & 94 & 86.2 & 0.341 \\
\hline & $30-39$ & 8 & 14.5 & 47 & 85.5 & \\
\hline & $40+$ & 4 & 6.8 & 55 & 93.2 & \\
\hline \multirow[t]{2}{*}{ Nationality } & Saudi & 21 & 12.1 & 152 & 87.9 & 1.000 \\
\hline & Non-Saudi & 6 & 12.0 & 44 & 88.0 & \\
\hline \multirow[t]{4}{*}{ Body mass index groups } & Underweight & 0 & 0.0 & 4 & 100.0 & 0.959 \\
\hline & Normal weight & 10 & 13.3 & 65 & 86.7 & \\
\hline & Overweight & 9 & 11.5 & 69 & 88.5 & \\
\hline & Obese & 7 & 11.1 & 56 & 88.9 & \\
\hline \multirow[t]{2}{*}{ Travel history outside KSA during the last six months? } & No & 24 & 11.4 & 187 & 88.6 & 0.165 \\
\hline & Yes & 3 & 25.0 & 9 & 75.0 & \\
\hline \multirow[t]{3}{*}{ Smoke or use tobacco products } & No & 16 & 10.5 & 136 & 89.5 & 0.199 \\
\hline & Yes & 11 & 18.0 & 50 & 82.0 & \\
\hline & Ex-smoker & 0 & 0.0 & 10 & 100.0 & \\
\hline \multirow[t]{4}{*}{ Number of Flu per year } & I time & 16 & 14.7 & 93 & 85.3 & 0.712 \\
\hline & 2 times & 9 & 11.0 & 73 & 89.0 & \\
\hline & 3 times & 2 & 8.3 & 22 & 91.7 & \\
\hline & More than 3 times & 0 & 0.0 & 8 & 100.0 & \\
\hline
\end{tabular}

damage to the olfactory epithelium. ${ }^{24}$ Moreover, viruses that can use the olfactory nerve as a route into the central nervous system include influenza A virus, herpes viruses, poliovirus, rabies virus, parainfluenza virus, adenoviruses, and Japanese encephalitis virus. ${ }^{23}$ In mouse models, transneuronal penetration of SARS-CoV-2 is demonstrated through the olfactory bulb, and its infection resulted in the rapid, transneuronal spread of the virus to related areas of the brain. ${ }^{25}$

A recent Korean study reported that anosmia and ageusia were observed in $15.3 \%$ of patients in the early stage of COVID-19 and $15.7 \%$ of patients with asymptomatic-tomild disease severity. Most patients with anosmia or ageusia recovered within three weeks and seem to be part of essential symptoms and clues for the diagnosis of COVID19 , particularly in the early stage of the disease. ${ }^{25}$

\section{Conclusion}

The top five clinical manifestations of mild SARS-CoV-2 infections were general fatigue, headache, cough, anosmia, and ageusia. Only $12 \%$ of confirmed COVID-19 cases were asymptomatic.

\section{Ethics Approval}

The Institutional Review Board of Imam Mohammad Ibn Saud Islamic University has approved this study under project number 22-2020 session 32 dated May 7, 2020. The general directorate for research and studies at Saudi MOH under IRB number 20-147E dated Jun 20, 2020. The study was also registered in the Saudi FDA under SCTR no. 20051303 dated Jun 29, 2020, and it was according to the declaration of Helsinki. 


\section{Acknowledgment}

The authors would like to thank Al-Subaie and Abdulaziz Al-Jomaih Charitable Foundation for funding the research project. Many thanks and gratitude goes to Athar Health Volunteering Society for their continuous support. Special thanks also go to all supporting staff at Riyadh quarantines. Heartfelt appreciation goes to our residents and interns who did a great job on study recruitment and follow-up.

\section{Funding}

This research project was partially funded by Al-Subaie Charitable Foundation and Abdulaziz Al-Jomaih Charitable Foundation.

\section{Disclosure}

The authors have no conflicts of interest to declare. All coauthors have seen and agree with the manuscript's contents, and there is no financial interest to report. Moreover, the authors certify that the submission is original work and is not under review at any other publication.

\section{References}

1. Zhu N, Zhang D, Wang W, et al. A Novel Coronavirus from patients with Pneumonia in China, 2019. N Engl J Med. 2020;382(8):727733. doi:10.1056/NEJMoa2001017

2. Phan LT, Nguyen TV, Luong QC, et al. Importation and human-tohuman transmission of a Novel Coronavirus in Vietnam. $N$ Engl J Med. 2020;382(9):872-874. doi:10.1056/NEJMc2001272

3. Holshue ML, DeBolt C, Lindquist S, et al. First case of 2019 Novel Coronavirus in the United States. N Engl J Med. 2020;382(10):929936. doi:10.1056/NEJMoa2001191

4. Mao L, Jin H, Wang M, et al. Neurologic manifestations of hospitalized patients with Coronavirus disease 2019 in Wuhan, China. JAMA Neurol. 2020;77(6):683. doi:10.1001/jamaneurol.2020.1127

5. Pan L, Mu M, Yang P, et al. Clinical characteristics of COVID-19 patients with digestive symptoms in Hubei, China: a descriptive, cross-sectional, multicenter study. Am J Gastroenterol. 2020;115 (5):766-773. doi:10.14309/ajg.0000000000000620

6. Al Mutair A, Alhumaid S, Alhuqbani WN, et al. Clinical, epidemiological, and laboratory characteristics of mild-to-moderate COVID19 patients in Saudi Arabia: an observational cohort study. Eur J Med Res. 2020;25(1):61. doi:10.1186/s40001-020-00462-x

7. Borges Do Nascimento IJ, Cacic N, Abdulazeem HM, et al. Novel Coronavirus infection (COVID-19) in humans: a scoping review and meta-analysis. JCM. 2020;9(4):941. doi:10.3390/jcm9040941

8. Zhang X, Cai H, Hu J, et al. Epidemiological, clinical characteristics of cases of SARS-CoV-2 infection with abnormal imaging findings. Int J Infect Dis. 2020;94:81-87. doi:10.1016/j.ijid.2020.03.040

9. Chen T, Wu D, Chen H, et al. Clinical characteristics of 113 deceased patients with coronavirus disease 2019: retrospective study. $B M J$. 2020;26:m1091. doi:10.1136/bmj.m1091

10. Tian S, Hu N, Lou J, et al. Characteristics of COVID-19 infection in Beijing. J Infect. 2020;80(4):401-406. doi:10.1016/j.jinf.2020.02.018
11. de Haro-licer J, Roura-Moreno J, Vizitiu A, González-Fernández A, González-Ares JA. Long term serious olfactory loss in colds and/or flu. Acta Otorrinolaringologica. 2013;64(5):331-338. doi:10.1016/j. otorri.2013.04.003

12. Suzuki M, Saito K, Min W-P, et al. Identification of viruses in patients with postviral olfactory dysfunction. Laryngoscope. 2007;117(2):272-277. doi:10.1097/01.mlg.0000249922.37381.1e

13. Yamagishi M, Fujiwara M, Nakamura $H$. Olfactory mucosal findings and clinical course in patients with olfactory disorders following upper respiratory viral infection. Rhinology. 1994;32(3):113-118.

14. Vaira LA, Salzano G, Deiana G, De Riu G. Anosmia and ageusia: common findings in COVID-19 patients. Laryngoscope. 2020;130 (7):1787. doi:10.1002/lary.28692

15. Han C, Duan C, Zhang S, et al. Digestive symptoms in COVID-19 patients with mild disease severity: clinical presentation, stool viral RNA testing, and outcomes. Am J Gastroenterol. 2020;115(6):916923. doi:10.14309/ajg.0000000000000664

16. Soeroto AY, Soetedjo NN, Purwiga A, et al. Effect of increased BMI and obesity on the outcome of COVID-19 adult patients: a systematic review and meta-analysis. Diabetes Metabol Syndr. 2020;14 (6):1897-1904. doi:10.1016/j.dsx.2020.09.029

17. Kashyap VK, Dhasmana A, Massey A, et al. Smoking and COVID19: adding fuel to the flame. IJMS. 2020;21(18):6581. doi:10.3390/ ijms21186581

18. Machhi J, Herskovitz J, Senan AM, et al. The natural history, pathobiology, and clinical manifestations of SARS-CoV-2 infections. $J$ Neuroimmune Pharmacol. 2020;15(3):359-386. doi:10.1007/ s11481-020-09944-5

19. Kronbichler A, Kresse D, Yoon S, Lee KH, Effenberger M, Shin JI. Asymptomatic patients as a source of COVID-19 infections: a systematic review and meta-analysis. Int J Infect Dis. 2020;98:180-186. doi:10.1016/j.ijid.2020.06.052

20. Kim G-U, Kim M-J, Ra SH, et al. Clinical characteristics of asymptomatic and symptomatic patients with mild COVID-19. Clin Microbiol Infect. 2020;26(7):948.e1-948.e3. doi:10.1016/j. cmi.2020.04.040

21. Yu P, Zhu J, Zhang Z, Han Y, Familial A. Cluster of infection associated with the 2019 Novel Coronavirus indicating possible person-to-person transmission during the incubation period. J Infect Dis. 2020;221(11):1757-1761. doi:10.1093/infdis/jiaa077

22. Hoehl S, Rabenau H, Berger A, et al. Evidence of SARS-CoV-2 infection in returning travelers from Wuhan, China. $N$ Engl J Med. 2020;382:1278-1280. doi:10.1056/NEJMc2001899

23. van Riel D, Verdijk R, Kuiken T. The olfactory nerve: a shortcut for influenza and other viral diseases into the central nervous system: the olfactory nerve: a shortcut for viruses into the CNS. J Pathol. 2015;235(2):277-287. doi:10.1002/path.4461

24. Bagheri SH, Asghari A, Farhadi M, et al. Coincidence of COVID-19 epidemic and olfactory dysfunction outbreak in Iran. Med J Islam Repub Iran. 2020;34:62. doi:10.34171/mjiri.34.62

25. Lee Y, Min P, Lee S, Kim S-W. Prevalence and duration of acute loss of smell or taste in COVID-19 patients. J Korean Med Sci. 2020;35 (18):e174. doi:10.3346/jkms.2020.35.e174 


\section{Publish your work in this journal}

The Journal of Multidisciplinary Healthcare is an international, peerreviewed open-access journal that aims to represent and publish research in healthcare areas delivered by practitioners of different disciplines. This includes studies and reviews conducted by multidisciplinary teams as well as research which evaluates the results or conduct of such teams or healthcare processes in general. The journal

covers a very wide range of areas and welcomes submissions from practitioners at all levels, from all over the world. The manuscript management system is completely online and includes a very quick and fair peer-review system. Visit http://www.dovepress.com/testimonials. php to read real quotes from published authors. 